\section{SCI-FI DENTISTRY}

E ectric toothbrushes, air flossers, CAD-CAM, 3D printing ... dental technology has made incredible advances in the last 50 years, but where will we be in the next 50 ? If the workers who produced the labour-intensive oxen thigh bone toothbrushes in the early twentieth century ${ }^{1}$ had glimpsed the future of 2014, it would have seemed like science fiction. Here we look at dental innovations in three key areas that are helping to shape the future for dentists.

\section{Education}

Virtual simulation is changing the way students learn. Threedimensional virtual mouths can be used by dental professionals in training and are similar to flight simulators for pilot training, with sensory controllers to help simulate resistance felt when drilling into healthy or decaying teeth. Unlike work on mannequins in the past, virtual environments can accurately assess success, highlighting areas in technique that need improving. Professor Paul Brunton, Director of Student Education at the University of Leeds, argues students of the digital generation need the kind of stimulus 3D virtual mouths can provide: 'They seem to learn by osmosis, absorbing the information in a fun and interactive way. Some of my students liken it to a dental Wii.'

The University of Leeds has been a pioneer in 'futuristic' learning and Professor Brunton envisages further 3D simulation is the future for initial training and revalidation: 'Digital virtual patients will be developed for undergraduate and postgraduate student education and I think digital decision support will come to the fore - so Star Trek wasn't that futuristic after all!'

The importance of practising techniques under life-like conditions prior to entering a clinic cannot be underestimated but Professor Damien Walmsley

\section{ARE BIONIC TEETH THE FUTURE?}

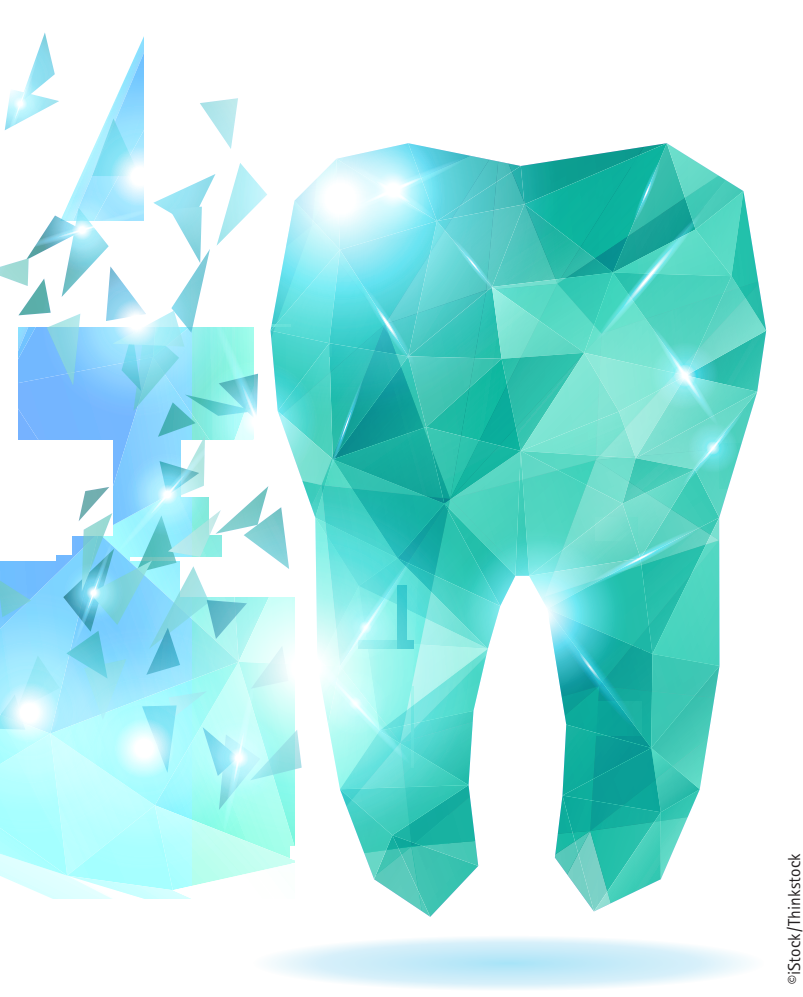

recognises that virtual simulation is not the only exciting development within education at the moment:

'Advances in technology will allow improved communication, better access to learning materials and the ability to supplement traditional teaching. With the advent of mobile technology, students have immediate access to such material via powerful hand held workstations.' The Internet and the advent of mobile apps have diversified the information available to students, as well as the public, and peer reviewing of all online data and healthcare apps will need to be best practice for the future. ${ }^{2}$ While Professor Walmsley still envisages some kind of traditional classroom model being used in 50 years' time as the student-patient-teacher unit will always be central to dental education, it is fair to say that with the speed of developments in teaching technology, the

'One of the most exciting areas of development in dentistry is in dental regeneration and caries prevention. Bioactive replacements for dentine are changing the way dentists fight decay and think about dental treatment...' 'traditional classroom' may be unimaginably high tech in the future.

\section{Technology}

CAD-CAM and accurate 3D printing may threaten the idea of the traditional dental lab, with crowns being made in a day and perhaps dental implants and dentures being produced in mere seconds in the future, but John Battersby suggests that even with 'sci-fi' technology the dental technician will remain essential. ${ }^{3}$ While the digital generation are comfortable with new techniques and equipment, most dentists still practise as they were taught in dental school, so adoption of new technology is far slower than its invention: 'Rather than being the death of the traditional dental lab, digital technologies and especially the latest materials and manufacturing technologies are likely to see a growing demand for prosthetics and restoration work as they bring them within reach of more people. ${ }^{3}$

Yet can we accurately predict what the future of 3D printing may have in store for dentistry? Walmsley thinks not: 'In some ways our imagination of what we can do has not fully caught up with this technology. It's not all about big technology though and in an age where everything from laptops to phones are getting smaller, 'wearable tech' such as glasses, watches and clothes could become commonplace.

\section{Biological regeneration}

One of the most exciting areas of development in dentistry, however, is in dental regeneration and caries prevention. Without having to look too far into the future, bioactive replacements for dentine are changing the way dentists fight decay and think about dental treatment, as Professor Alastair Sloan suggests: 'I see the development of more biologically active restorations - fillings that harness the natural repair process or encourage repair - as being the most exciting advances in regenerative dentistry as these are likely to be the most translational research areas at present.' 
A big part of future regenerative medicine rests on stem cell research and we have still not seen the full impact of stem cell technology. So will we be growing new teeth in 50 years' time? Dr Ana Angelova Volponi's current research centres on finding a source of mesenchymal stem cells that are able to maintain toothforming ability and can be easily expanded in laboratory settings: 'Research focused on generating a "biotooth" has made big steps forward by using human adult gingival stem cells as one of the sources in the creation of a whole biotooth, where all anatomical parts of a tooth are present. ${ }^{4}$ Yet others, such as Professor Sloan, do not foresee growing teeth as the future for dentistry, with stem cell technology able to overcome all dental damage: 'It may be possible, but will it be clinically practicable?'

The regenerative approach to periodontology is developing rapidly, as Dr Angelova Volponi asserts: 'Often we see a combination of cell-based therapy, gene therapy and application of scaffolds to deliver cells and genes for periodontal regeneration - even 3D printed scaffolds have been shown to be useful in this area. ${ }^{5}$

Perhaps in half a century many of these treatments will be seen in the dental clinic.

1. Oxen thigh bones to make wartime brushes. Br Dent J 2014; 217: 61.

2. Khatoon B, Hill K B, Walmsley A D. Can we learn, teach and practise dentistry anywhere, anytime? Br Dent J 2013; 215: 345-347.

3. Battersby J. Is CAD/CAM the end for dental labs? BDJ Team 2014; doi:10.1038/ bdjteam.2014.63.

4. Angelova Volponi A, Kawasaki M, Sharpe P T. Adult human gingival epithelial cells as a source for whole-tooth bioengineering. J Dent Res 2013: 92: 329-334.

5. Park C H, Rios H F, Taut A D et al. Imagebased, fiber guiding scaffolds: a platform for regenerating tissue interfaces. Tissue Eng Part C Methods 2014; 20: 533-542.

BY LAURA PACEY

This is Laura's final piece for the Journal. We would like to thank her for all of her hard work and valued contributions during her time on the editorial team.

\section{BDA FIGHTS FOR FAIR FEES AND DECENT REGULATION}

On 17 October 2014 the British Dental Association (BDA) announced that it has initiated judicial review proceedings against the General Dental Council (GDC).

The GDC, which has faced heavy criticism from the Professional Standards Authority on the way it deals with patient complaints, has recently announced its desire to increase the professional fees paid by dentists by $64 \%$. The BDA has accused the GDC of failing to provide clear evidence of the policy or business case that have underpinned the mooted fee rise - rendering the regulator's case unlawful.

Mick Armstrong, Chair of the BDA's Principal Executive Committee, said: 'We are being asked to pay the price for our regulator's mismanagement, and we won't stand for it. We are determined to fight for fair fees and decent regulation. We have given the GDC every opportunity to demonstrate they have built a reasoned, evidenced and lawful case for this fee hike. They have chosen not to respond, and now we will leave it to the courts to decide'.

GDC plans would see dentists fees rise from $£ 576$ to $£ 945$ - the highest fee charged by any comparable healthcare regulator, and they will have no choice but to pay, as they must be registered with the GDC in order for them to practise lawfully.

\section{GDC pledges openness and honesty}

The GDC is among eight UK professional healthcare regulators to publish a joint statement, setting out their commitment to a duty of candour for healthcare professionals, and pledging to do more to put openness and honesty at the heart of healthcare.

This joint statement is a milestone in ensuring universality across all the professions. This common duty makes clear to patients what they can and should expect of those who treat them and give them confidence that, should professionals fall short of those expectations, regulators will respond accordingly.
The full statement on 'Openness and honesty - the professional duty of candour' can be read at: http://image.s4.exct.net/ lib/fe921570706d027d7d/m/1/Joi nt+statement+on+candour+13+ Oct+2014.pdf.

Dental professionals understand their ethical duty

The Dental Defence Union (DDU), in responding to the joint statement by eight UK health regulators on the importance of being open and honest with patients, said that dental professionals understand that candour is central to their relationship with their patient.

Rupert Hoppenbrouwers, Head of the DDU, said: 'While we welcome the emphasis being placed on candour by the GDC and other regulators, our experience is that dental professionals overwhelmingly understand their longstanding ethical duty to be open and honest with patients.

'They appreciate that having an open dialogue with patients is not something to be afraid of. When something goes wrong, dental professionals tell us time and again that apologising early to the patient or their family can help resolve a complaint more quickly or prevent one altogether - so it's to everybody's advantage to be open and honest from the outset'

\section{BDA-BDJ WINTER LECTURE 2014}

The BDA-BDJ Winter Lecture 2014 will be given by Dr Michele Barbour (pictured), Senior Lecturer in Dental Biomaterials at the University of Bristol, on 10 December 2014.

Dr Barbour, who is also head of the University of Bristol's Oral Nanoscience research group, focusses research on the application of nanotechnology to dental materials and, in particular, the design and synthesis of antimicrobial nanoparticles for applications in dentistry.

Taking place at the BDA offices in London, Dr Barbour will review the ever changing world of dental materials and determine exactly what benefits these 'new' materials offer, and how they differ from what came before. She will then discuss the exciting directions that dental materials will take in the future.

The Winter Lecture is sponsored by the Wrigley Oral Healthcare Programme and a festive reception will follow the lecture. One hour of verifiable continuing professional development (CPD) is available for those attending.

Tickets are complimentary for BDA members and will be allocated by a ballot which closes on 19 November. To apply, visit www.bda.org/winterlecture or email winterlecture@bda.org.

A recording of the lecture will be made available after the event for all members to view online. 